\title{
Introduction to the Special Issue of the ECE statistical journal dedicated to the measurement of VAW
}

Violence against women is now recognized as a form of discrimination against women and a fundamental violation of women's human rights, with increased attention being paid to its measurement. The 1995 Beijing Platform for Action provided significant impetus to strengthening the knowledge base when it specifically highlighted the lack of data on violence against women (VAW). The Platform exhorted governments to build national statistical capacity and research to collect data and disseminate findings, in coordination with universities and organizations from civil society to guide policy and institutional reforms on VAW. ${ }^{1}$

In the last ten years some national statistical offices, United Nations entities and other national, international and regional organizations, non-governmental organizations and researchers have done substantial work to strengthen survey methodologies, develop common indicators and address the challenges of comparing data over time, and between different countries and regions. However, there is still a chronic lack of relevant data on the nature, prevalence and incidence of the various types of violence against women, particularly in some regions. Lack of such data continues to be highlighted as a major concern and barrier to effective policy - making to prevent and eliminate violence against women.

On 22 December 2003, the General Assembly of the United Nations adopted by consensus a resolution requesting the Secretary-General to conduct an in-depth study on all forms and manifestations of violence against women. The resolution requested that the study provide, among other aspects, "a statistical overview on all forms of violence against women, in order to evaluate better the scale of such violence, while identifying gaps in data collection and formulating proposals for assessing the extent of the problem". ${ }^{2}$ In the context of preparing the study, an Expert Group Meeting on Violence against women: a statistical overview, challenges and gaps in data collection and methodology and approaches for overcoming them was organized by the UN Division for the Advancement of Women in collaboration with the United Nations Economic Commission for Europe (UNECE) and the World Health Organisation (WHO), (Geneva, April 2005). ${ }^{3}$ The Secretary-General's study will be submitted to the sixty-first session of the General Assembly of the United Nations (fall of 2006).

This special issue of the ECE Statistical Journal is a contribution to the preparation of the SecretaryGeneral's study. It collects some of the papers presented at the Expert Group Meeting, as well as papers from other meetings that focused on the implementation of national surveys to measure VAW (such as the ECE Work Session on Gender Statistics, Geneva, October 2004 and the European conference on interpersonal violence, Paris September 2005). The purpose of this collection is to summarize

\footnotetext{
${ }^{1}$ Beijing Platform for Action, Strategic objectives H3 and D2, para 1-9a, 206.

${ }^{2}$ UN Resolution A/RES/58/185.

${ }^{3} \mathrm{http} / / / w w w . u n . o r g /$ womenwatch/daw/egm/vaw-stat-2005/index.html.
} 
the experience accumulated in the measurement of VAW within the framework of official statistics, particularly in relation to the use of population surveys. It also intends to present the challenges that official statistics face in improving the data on VAW and suggest opportunities for overcoming them through a variety of means.

Police or court records have, until recently, been the most common sources of data used for assessing the scope of VAW, but these sources have several limitations. Although there is scope for improving police or courts records to better reflect gender-specific aspects in their collection, processing and dissemination, they remain a biased source of information on VAW. Given the sensitivity of the subject, the persistence of legal frameworks that fail to criminalize various forms of violence against women, as well as attitudes of law enforcement and justice personnel that dismiss women's claims, women tend to under-report the offences. As a consequence, statistics based on reported cases heavily underestimate the phenomenon.

Population-based surveys are a more reliable method for collecting information on the level of violence against women in a general population since women do not need to formally report such violence. Also, if properly designed, such surveys reflect the actual occurrences of victimization rather than what is reported to officials.

In addition to surveys designed and carried out by national statistical offices or other national institutions presented in this volume, international organizations such as $\mathrm{WHO}^{4}$ and the European Institute for Crime Prevention and Control (HEUNI) have developed survey methodologies and implemented them in several countries in a standardized format, with the aim of obtaining estimates on the prevalence of VAW which would allow for inter-country comparisons. Although these projects have often been implemented outside the framework of official statistics, they offer a sound methodology which, depending on the countries' needs and circumstances, can be used to design national surveys to measure VAW.

Other international programmes such as the Demographic and Health Surveys (DHS), managed by Macro International have included a specialized module on VAW -similar to the WHO instrument in some of their national surveys. Specialized modules are a good example of how countries can use on-going surveys to collect some information on VAW. At the same time, caution must be exercised in the use of this approach so as to ensure that the content and the operations of the on-going survey are compatible with the measurement of VAW and the safety requirements for both respondents and interviewers are guaranteed.

The 1993 United Nations Declaration on VAW ${ }^{5}$ provides a very broad and inclusive framework for studying violence against women. According to this definition, violence against women is defined as:

"Violence against women" means any act of gender-based violence that results in, or is likely to result in, physical, sexual or psychological harm or suffering to women, including threats of such acts, coercion or arbitrary deprivation of liberty, whether occurring in public or private life."

Specifically, the declaration outlines a broad variety of acts and circumstances that are included in this definition:

Physical, sexual and psychological violence occurring in the family, including battering; sexual abuse of female children in the household; dowry-related violence; marital rape; female genital mutilation; other traditional practices harmful to women; non- spousal violence; neglect and abuse of girl children; violence related to exploitation;

\footnotetext{
${ }^{4}$ See in particular WHO Multi-Country Study on Women's Health and Domestic Violence against Women, WHO 2005.

${ }^{5}$ See http://www.unhchr.ch/huridocda/huridoca.nsf/(Symbol)/A.RES.48.104.En?Opendocument.
} 
Physical, sexual and psychological violence occurring within the general community, including rape; sexual abuse; sexual harassment and intimidation at work, in educational institutions and elsewhere; trafficking in women; forced prostitution;

Physical, sexual and psychological violence perpetrated or condoned by the State, wherever it occurs.

This broad definition, and its subsequent further expansion in legal and policy instruments together with the practice of international and regional judicial and expert bodies show the complexity of the phenomenon and the challenges related to its measurement.

There is a great variety in the definitions used in surveys and the way information was collected. The major differences relate to:

- Definition of violence. Most surveys focused only on selected forms of violence against women, with intimate partner violence and sexual assault being the most commonly studied forms. Less attention has been given to other forms of violence, such as economic violence, stalking, and other psychological violence.

- Type of survey. Some surveys were designed with the specific purpose of only collecting data on VAW, others had a broader scope (victimization in general or health).

- Question design. Some surveys used broad questions, while others used multiple behaviourally specific questions (which had proven to be more effective).

- Reference period of victimization. This varied from lifetime, previous 6 months, one year, five years.

- Information collected on the victimization event. Some surveys collected information on frequency in terms of number of incidents, others measured duration. Different settings (home, school, workplace) and violence committed by different perpetrators were also considered.

- Mode of data collection. Some survey questionnaires were administrated through face-to-face interviews, others through telephone interviews, or self-compilation. Techniques such as CATI (computer-assisted telephone interviewing), CAPI (computer-assisted personal interviewing), and CASI (computer-assisted self-interviewing) were also used.

The experiences gained by national and international organizations are encouraging, as they have greatly advanced the development of survey methodology to study VAW. However, as presented in the report of the Expert Group Meeting "problems still exist with respect to both the reliability and validity of the data being collected, as well as with the comparability of data across studies. There is still a lack of standardized methods and instruments for data measurement and collection. Thus more work is needed to ensure greater uniformity and comparability in the collection and reporting of data on all forms of violence against women".

We hope that the present collection of papers, the WHO Multi-country Study and the SecretaryGeneral's forthcoming study on violence against women will give further impetus to strengthening the knowledge base about all forms and manifestations of violence against women, in all parts of the world.

Christine Brautigam, UN Division for the Advancement of Women Claudia Garcia Moreno, World Health Organisation Angela Me, United Nations Economic Commission for Europe 